\title{
HIGH RESOLUTION SEISMIC REFLECTION METHODS TO DETECT NEAR SURFACE TUFF-CAVITIES: A CASE STUDY IN THE NEAPOLITAN AREA, ITALY
}

\author{
Vincenzo Di Fiore ${ }^{1}$, Antimo Angelino ${ }^{1}$, Salvatore Passaro $^{*}$, And Angelo Bonanno 2
}

\begin{abstract}
The Neapolitan region of Italy is plagued by the presence of shallow manmade cavities in lithoid tuffs that cause problems for communities because they produce building damages and loss of human lives. A high resolution P-wave seismic-reflection technique was successfully used to define a cavity $6 \mathrm{~m}$ by $10 \mathrm{~m}$ in horizontal dimensions and with a height of about $6 \mathrm{~m}$ located in a tuff layer 10 to $19 \mathrm{~m}$ below ground level. Such a cavity was located at Afragola (near Naples) where the local geology is typical of the Neapolitan area. The seismic dataset was acquired by using end-on spread geometry, with $0.25 \mathrm{~m}$ spacing for shots and $0.5 \mathrm{~m}$ for receivers. The application of band-pass filtering $(30-150 \mathrm{~Hz})$ allowed us to remove incoherent noise from the data, while an additional equivalent slope $\left(\mathrm{Vs}^{-1}\right)$ of $0.005 \mathrm{~s} \mathrm{~m}^{-1}$ cut in the $\mathrm{FK}$ transform results in ground-roll noise removal. Both the acquisition and processing methods have been necessary to investigate and define the shape and dimensions of the targeted cavity.
\end{abstract}

\section{INTRODUCTION}

An important problem in civil engineering is the detection of natural and man-made cavities, because they often produce subsurface subsidence and collapses. This problem is particularly frequent when dealing with karst terranes, where natural cavities are formed from rock dissolution. Of course, the detection of cavities is mainly carried out by using geophysical prospecting methods, but the interaction of several factors, such as porosity, groundwater, locally complex geological contexts, and logistics may result in severe uncertainty as to the best choice for geophysical techniques. Electrical-resistivity tomography may be appropriate in dolomitic rocks (e.g., van Schoore, 2002) as well as in masses of flysh (e.g., Pánek et al., 2010), while groundpenetrating radar gives optimal results for shallow cavities in the absence of groundwater (Grandjean and Leparoux, 2004) or in glacial environments (Taurisano et al., 2006). Highresolution seismic-reflection methods can be used to detect shallow cavities. The extreme contrast of elastic properties between a water- or air-filled void and the surrounding rocks provides an excellent reflecting interface. Several authors (Hunter et al., 1984; Branham and Steeples, 1988; Steeples and Miller, 1987, 1990; Miller and Steeples, 1991; Bruno and Rapolla, 1997; Inazaki et al., 2004) applied high resolution reflections of seismic P-waves to detect cavities, including evaluating the risk of an active sinkhole located at $7 \mathrm{~m}$ depth in $0.6 \mathrm{~m}$ thick coal seam (Miller and Steeples, 1991). Inazaki et al. (2004) successfully applied the seismic-reflection technique to detect cavities smaller than $2 \mathrm{~m}$ in diameter located 5 to $10 \mathrm{~m}$ in depth.

However, many authors suggest the use of more than one geophysical prospecting technique to reduce the ambiguities inherent in each method (Pueyo-Anchuela et al., 2010; Frumkin et al., 2011).
In the Campanian Region and in the Neapolitan area, in particular, there are several sites characterized by the presence of shallow cavities between 10 and 50 meters in depth in lithoid tuff that was extensively quarried in historical times for building materials. We designed a highresolution seismic-reflection survey to maximize the potential for detection of the shape and dimensions of a lithoid tuff cavity located at Afragola, Naples. Shallow voids in tuff in urbanized areas are a known problem in the Campanian Plain, and they often produce heavy damages and loss of human lives as a consequence of collapses, such as that at Casalnuovo di Napoli in August 2011, the last fatal event. Cavities are often located in the urban areas and buildings are located above them. Therefore, they represent a clear threat to the stability of the buildings, as can be seen by the large number of edifices damaged by collapse into the cavity underneath. Often the locations of the cavities are unknown, because they are not recorded, location maps are not available, or access holes are concealed. Some cavities are located at small sites in urbanized areas where it is difficult to use geophysical methods such seismic refraction or electrical resistivity. A search for these cavities is important to reduce the risk; and therefore, it is important to develop a non-invasive survey method.

A seismic profile was acquired for this cavity by using specifically adapted parameters to allow for the best result for the investigated area. The result obtained was compared with the theoretical model using the finite

\footnotetext{
* Corresponding Author: salvatore.passaro@cnr.it

${ }^{1}$ Istituto per l'Ambiente Marino Costiero, CNR - Calata Porta di Massa Porto di Napoli, 80 - 80133 Naples - Italy

${ }^{2}$ Istituto per l'Ambiente Marino Costiero, CNR - Sezione di Capo Granitola, Via del Faro, 3 - 91021 Campobello di Mazara (TP) - Italy
} 


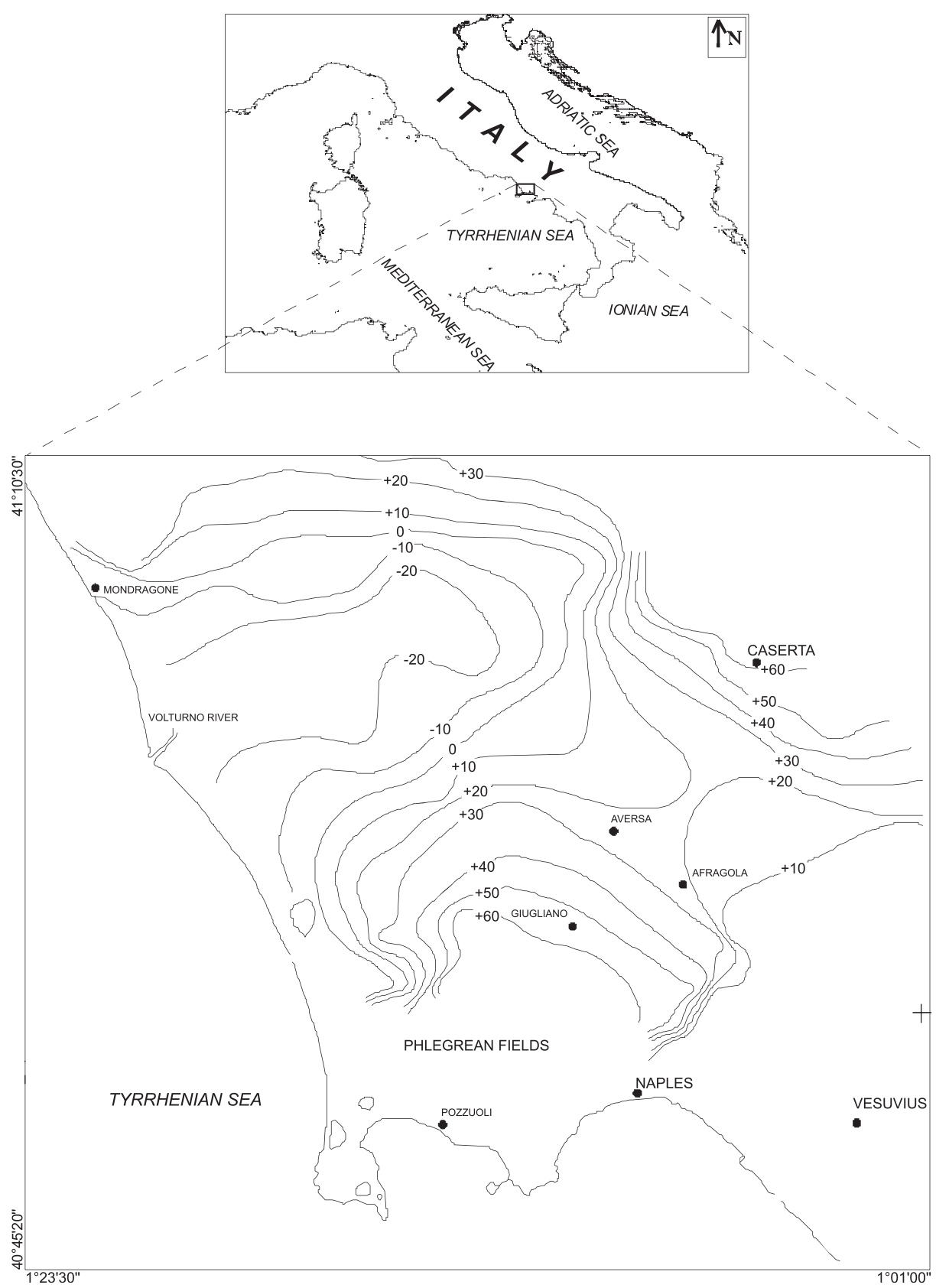

Figure 1. Distribution of the Ignimbrite Campana geological formation, a diffuse lithoid tuff, in the Campanian Plain (modified after Ortolani and Aprile, 1985). Contours are the top of the formation with respect to mean sea level.

differences method (Kelly et al., 1976; Kelly and Marfurt, 1990).

\section{Case Study in the Neapolitan Area}

The study area belongs to Roman Volcanic Province (Ghiara et al., 1979), a K-alkaline volcanic area in which the activity started in the late Pliocene and early Pleistocene as a result of a regional strain field along northeast-southwest and, subordinately, northwest-southeast fracture systems. The main products of explosive events that occurred in this area are the Green Ischia Ignimbrite (age $55 \mathrm{Ka}$; Vezzoli, 1988), the Ignimbrite Campana (age $39 \mathrm{Ka}$; De Vivo et al., 2001), and the Neapolitan Yellow Tuff (age 14.5 Ka; Deino et al., 2004).

The Ignimbrite Campana, or Campania Gray Tuff, is a widespread tuff formation (Fig. 1) often outcropping in the Campania Plain. It is located above the transitional marine deposits related to the isotope sub-stage 3.3, dated 55 to 50 ka B.P. (Romano et al., 1994). The Ignimbrite Campana represents the largest volcanoclastic formation of the Quaternary in southern Italy, and it extends over an area 


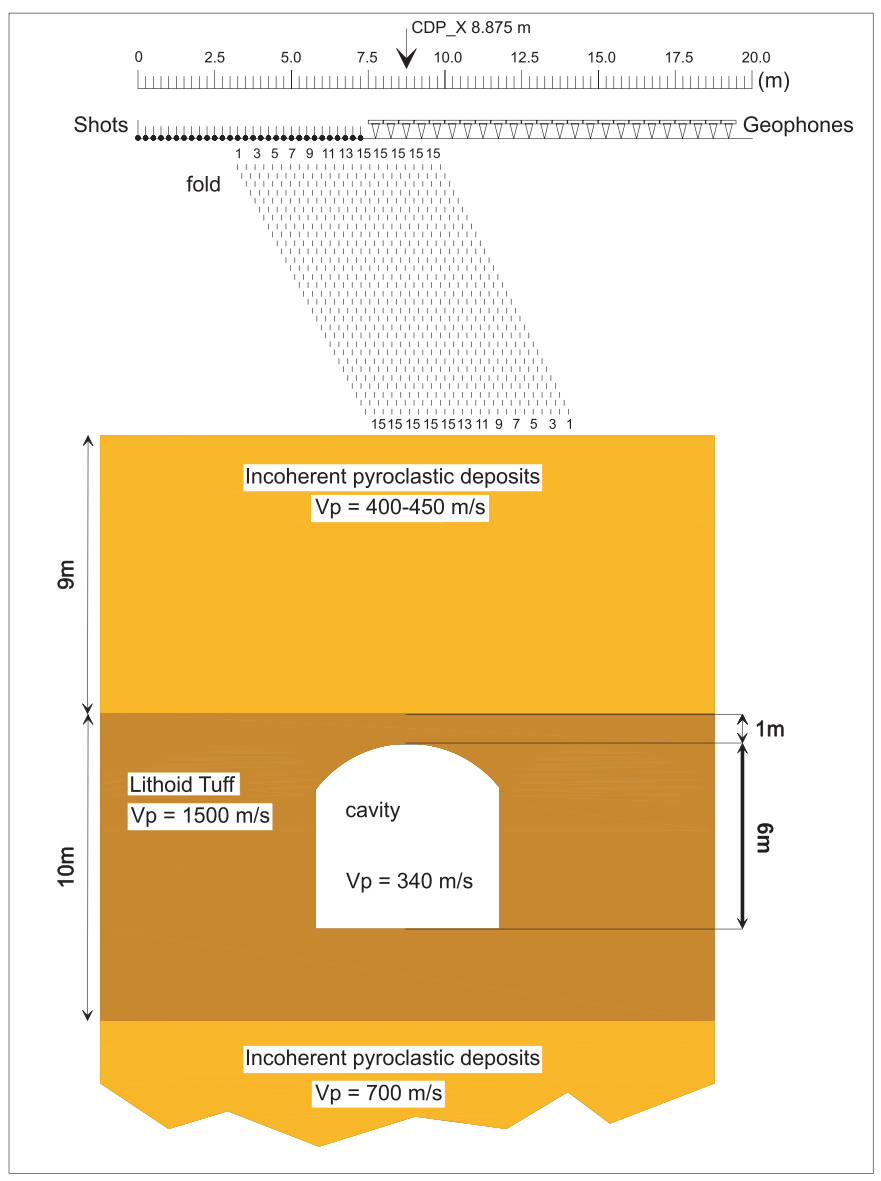

Figure 2. Field geometry and the P-wave velocity profile obtained by seismic downhole survey. The location of the CDP $8.875 \mathrm{~m}$ is shown.

of approximately $10,000 \mathrm{~km}^{2}$. Figure 1 shows the trend of the top of the formation; it increases in depth in the areas surrounding the Campanian Plain towards the Volturno River.

To verify the effectiveness of the high resolution seismic-reflection method, we acquired a seismic dataset on a site with a known cavity. This site was located at Afragola, near Naples, where the local geology is typical of the Neapolitan area.

The cavity was man-made for the extraction of building material, and its presence was known before the seismic survey. Speleologists roughly mapped it. It has a vaulted roof with the top at about $10 \mathrm{~m}$ depth, overlain by $1 \mathrm{~m}$ of lithoid tuff and $9 \mathrm{~m}$ of incoherent pyroclastic deposits (Fig. 2). Its horizontal extent is 6 by $10 \mathrm{~m}$, and it is approximately $6 \mathrm{~m}$ high (Figs. 2 and 3). The arch of the ceiling is about $1 \mathrm{~m}$ deep. It lies in tuff material that has a thickness of $10 \mathrm{~m}$.

The data were recorded by a 24-bit, 24-channel seismograph (Geode-Geometrics) in SEG2 format. An anti-alias filter was applied with a $40 \mathrm{~dB} /$ octave roll-off with a $-40 \mathrm{~dB}$ point of $2000 \mathrm{~Hz}$. A hammer-shaped seismic source was adopted to reduce the risk related to wave propagation, since the data were recorded inside the city and fairly close to the surrounding buildings. The dataset was acquired using an end-on spread geometry (e.g., Sheriff and Geldart, 1995). The source interval was set to $0.25 \mathrm{~m}$, while the receiver spacing was $0.5 \mathrm{~m}$ (Fig. 2). The whole data acquisition consisted of thirty shot records. All horizontal distances were converted to the absolute scale of Figure 2. The acquisition parameters are summarized in Table 1. Figure 4 shows four raw shot gathers acquired at the site.

To improve the velocity-analysis control, we also carried out a downhole survey. For this, we utilized a hole of $30 \mathrm{~m}$ deep conditioned for the borehole test. The equipment consisted of a 24-bit seismograph equipped with double 3D geophones at $10 \mathrm{~Hz}$, arranged in an X-Y-Z pattern separated by $1 \mathrm{~m}$. The two orthogonal, horizontal geophones were used to detect shear-wave (S-wave) arrivals, while the vertical geophone was used to detect compression-wave (P-wave) arrivals. The downhole $\mathrm{P}$-wave source consisted of a hammer and an aluminium plate. To produce an identifiable $\mathrm{S}$ wave, the source should transmit energy to the ground with a particle motion transverse to the axis of the survey. We used an impulsive metal-beam S-wave source, a repeatable and reversible source. In the field, we applied a stack of three traces for any record.

\section{Data Processing and Results}

Weak features with low frequency and amplitude found in shot records are an indirect indication of the presence of a subsurface cavity. In addition, the presence of a subsurface cavity breaks off a reflected horizon in the seismic section when located near in depth to the reflecting horizon. Figure 5 reports shows the two-step seismic-sequence processing used. The main purposes of the applied processing are to increase the signal-to-noise ratio and the vertical and horizontal resolution. Both horizontal and vertical resolutions are controlled by the spectral content of the seismic signal. We know that the threshold for vertical resolution generally is one quarter of the dominant wavelength (Yilmaz, 1994). Horizontal resolution is how close two reflecting points can be situated horizontally and yet be recognized as two separate points rather than one.

The area that produces the reflection is known as the first Fresnel zone. Two reflecting points that fall within the Fresnel zone are indistinguishable on the seismograms. The Fresnel zone depends on wavelength and depth of the reflecting interface (Yilmaz, 1994).

\section{Data Processing}

Preliminary processing was performed to obtain a preliminary stacked section, essential to establishing the main sequence of processing. Our data were processed on a Linux machine using Seismic Unix software of the 


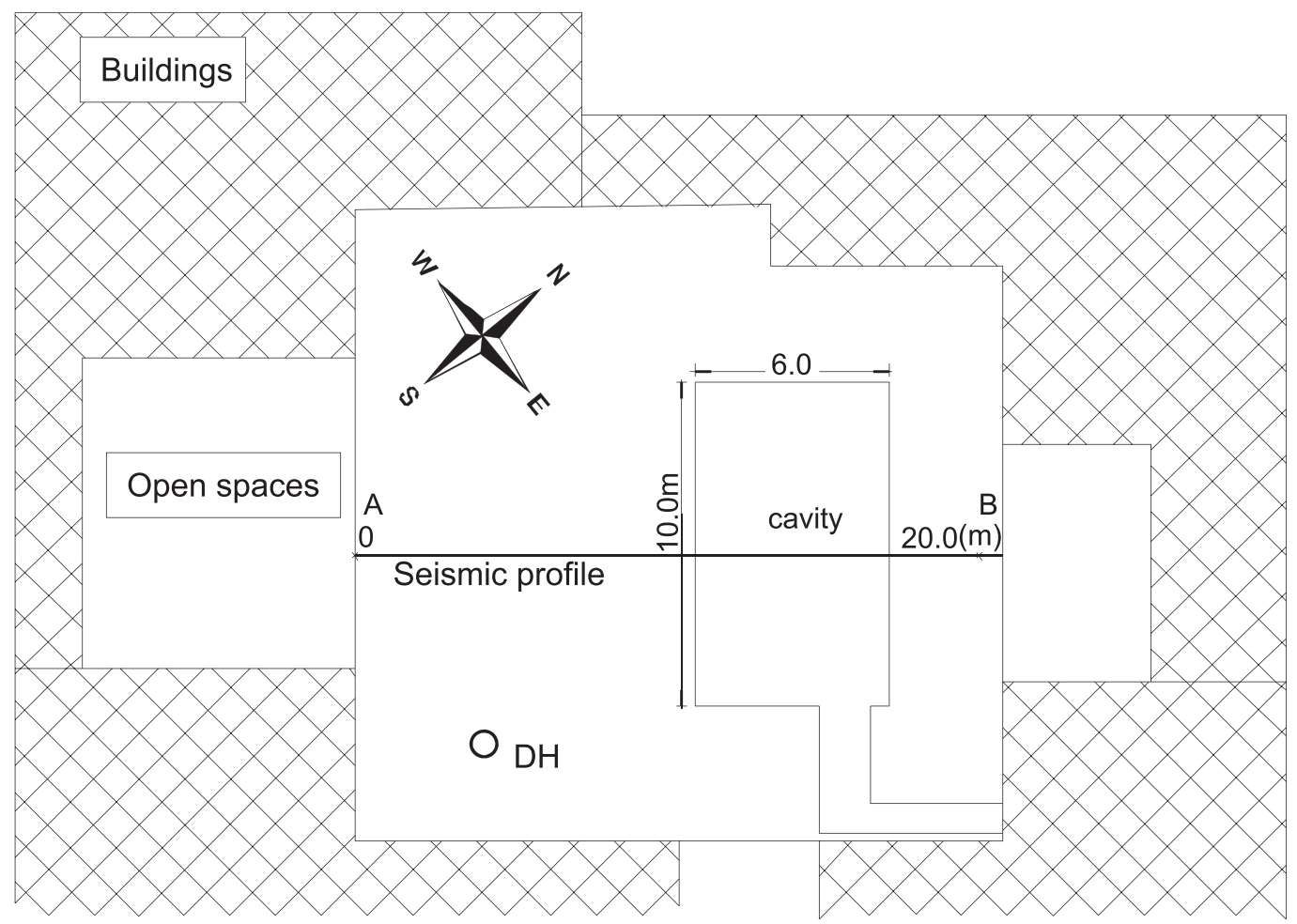

Figure 3. Site map located in Afragola, near Naples. The filled areas indicate the buildings, the white areas are open spaces. DH is the location of the down-hole survey that provided a 1D P-wave velocity field in Figure 2 and Table 2. The approximate outline of the mined cavity is shown, as is the route of the seismic line shown in Figure 2.

Colorado School of Mines (Center for Wave Phenomena, 2007). The processing was carried out using a basic CDP seismic-processing technique. A first check of the dataset was performed to estimate the data's quality. Top and surgical muting were applied to remove noise detrimental to the reflection events. Muting was concentrated in time and offset windows rich in refraction, direct wave, and airwave energy. Even though topography of the acquisition area was flat, the static corrections routine was used to minimize the effects of near-surface irregularities. In this

Table 1. Acquisition parameters P-wave.

\begin{tabular}{ll}
\hline Parameter & \multicolumn{1}{c}{ Specifics } \\
\hline Channels & 24 \\
Geophone interval & $0.5 \mathrm{~m}$ \\
Geophone type & $40-\mathrm{Hz}$ vertical \\
Shot interval & $0.25 \mathrm{~m}$ \\
Number of shots & 57 \\
Source & $10-\mathrm{kg}$ mallet on vertical steel plate \\
CDP bin size & $0.125 \mathrm{~m}$ \\
Maximum fold & 24 \\
Recording system & Geometrics Geode \\
Sample rate & $0.250 \mathrm{~ms}$ \\
Record length & $0.50 \mathrm{~s}$ \\
\hline
\end{tabular}

paper, we replaced conventional datuming static time shift correction with wave equation datuming (Dobrin, 1976).

\section{DAtA Filtering}

A second-order Butterworth filter $(-12 \mathrm{~dB})$ was applied to remove the incoherent low-frequency noise. A bandpass filter was designed by a low cut-off frequency at $30 \mathrm{~Hz}$ and a high cut-off frequency at $150 \mathrm{~Hz}$. The filtering was carried out by spectral analysis on the raw trace. An additional frequency wave number (FK) filtering was applied to the dataset to remove the ground roll noise from data, since this feature has low apparent velocity, and thus, can be easily removed in the FK domain. The fundamental parameter in FK filter design is the slope of the velocity that is to be removed or kept. Generally, in this soil type the ground roll has low apparent velocity, about 200 to $300 \mathrm{~m} / \mathrm{s}$. For this reason, taking the surface wave velocity Vs as $200 \mathrm{~m} \mathrm{~s}^{-1}$, we used an equivalent slope $\left(\mathrm{Vs}^{-1}\right)$ of $0.005 \mathrm{~s} \mathrm{~m}^{-1}$ as the fan filter.

\section{Velocity Analysis}

Velocity analysis was performed to estimate velocities for normal-move-out correction. Figure 6 represents an $8.875 \mathrm{~m}$ CDP_X having a maximum fold of fifteen traces (Fig. 2). The left panel of Figure 6 shows a raw CDP gather, where the ground-roll noise masks both the 


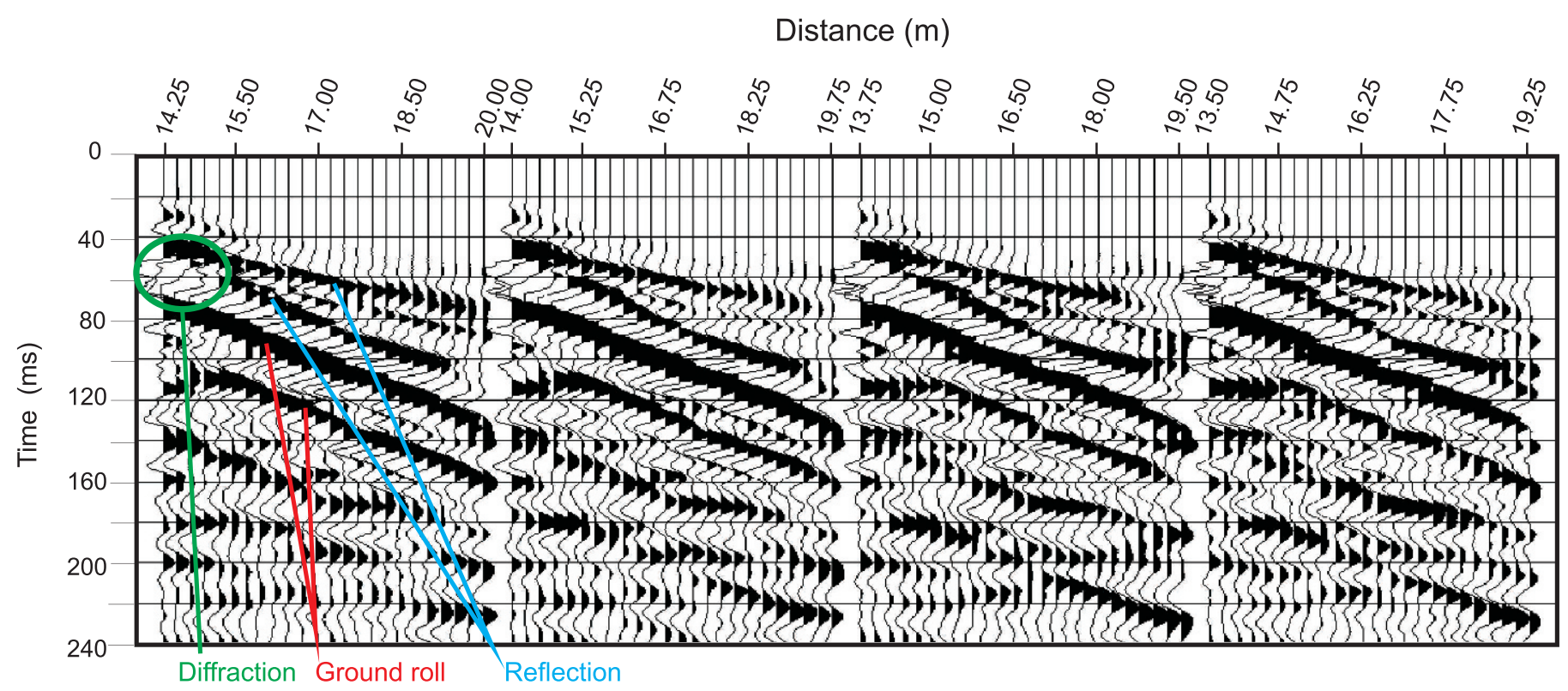

Figure 4. Four CDP gathers of raw data, with examples of direct (ground roll), refracted, and reflected phases. The presence of ground roll at low frequency and low apparent velocity is clear.

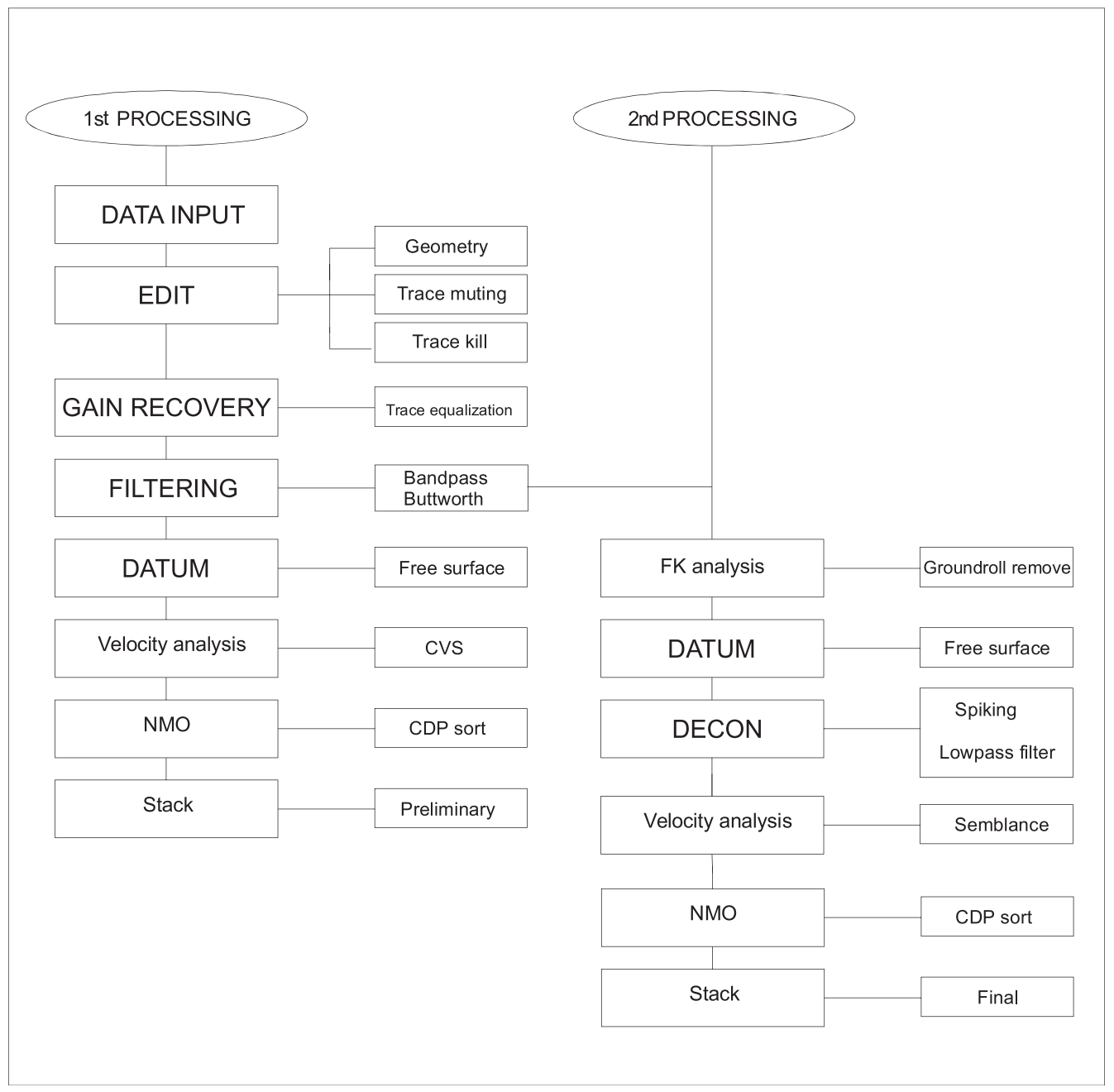

Figure 5. Processing sequences used to obtain the unmigrated final stacked section. 


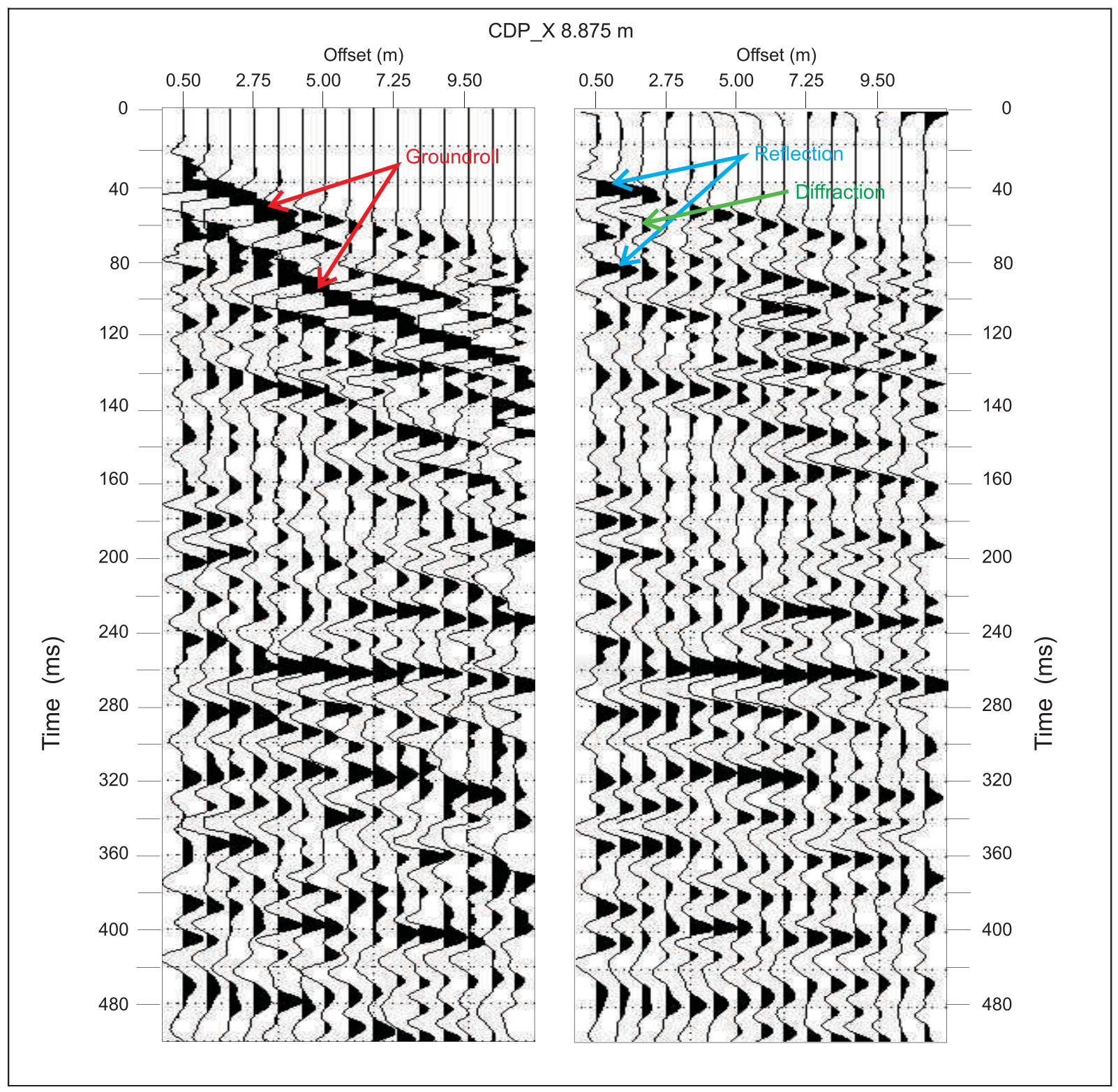

Figure 6. Comparison of CDP_X (8.875 m; fold=15) gather between raw data (on the left) and processed data (on the right). Note the improvement of the CDP_X data shown on the right panel, where is possible to detect the reflection and diffraction phases.

reflections and the diffractions. The right panel of Figure 6 shows the same data after the application of the processing sequence of Figure 5. Because of the higher attenuation of the ground roll, the data appear with a higher signal-tonoise ratio. The velocity was estimated by applying a semblance velocity analysis panel that provided a velocity field similar to the down-hole velocity field (Fig. 7) that was used as a guide to improve the choice of the best coherency peaks in the semblance panel. At this point, an unmigrated stack section was obtained that clearly shows the signal-to-noise ratio increasing due to the processing sequence applied (Fig. 8). In this stacked section, the diffraction is located at the CDP_X $8.875 \mathrm{~m}$ and at about $40 \mathrm{~ms}$ Two Way Time (TWT).
Forward Modelling

A seismic forward modeling method was applied to the velocity model of Figure 2 to compare the field data with the theoretical data. The main advantage of using finitedifference methods in seismic modeling is that they produce the complete wave field. The different wave-types (reflections, refractions, etc.) generally will appear in the computed solution with correct amplitudes and phases.

The finite difference method is a numerical method for solving partial differential equations, and it can be applied to seismic motion to compute the displacement at any point in the given geological model (Kelly et al., 1976). It can be applied both at the ground surface, for generating synthetic seismograms to be used for comparison with 


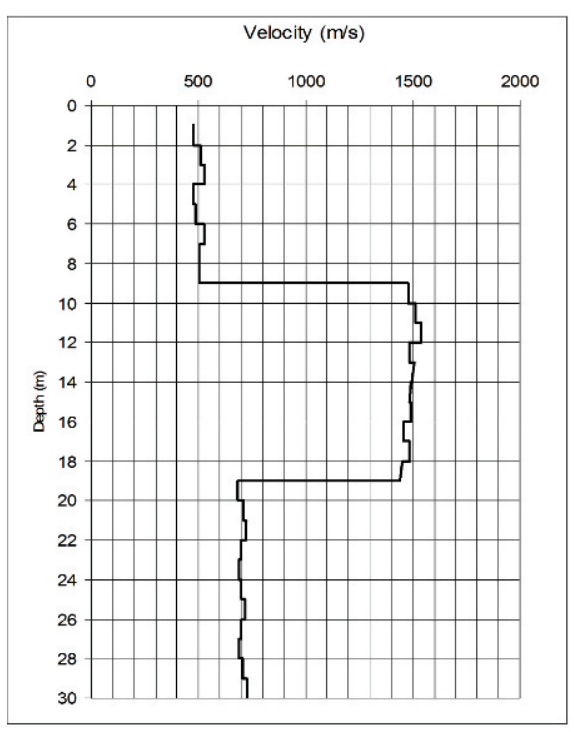

(A)

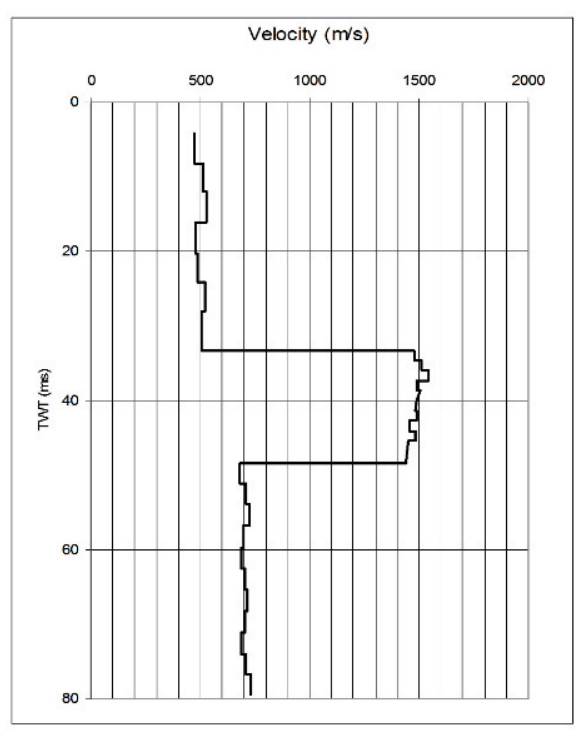

(B)

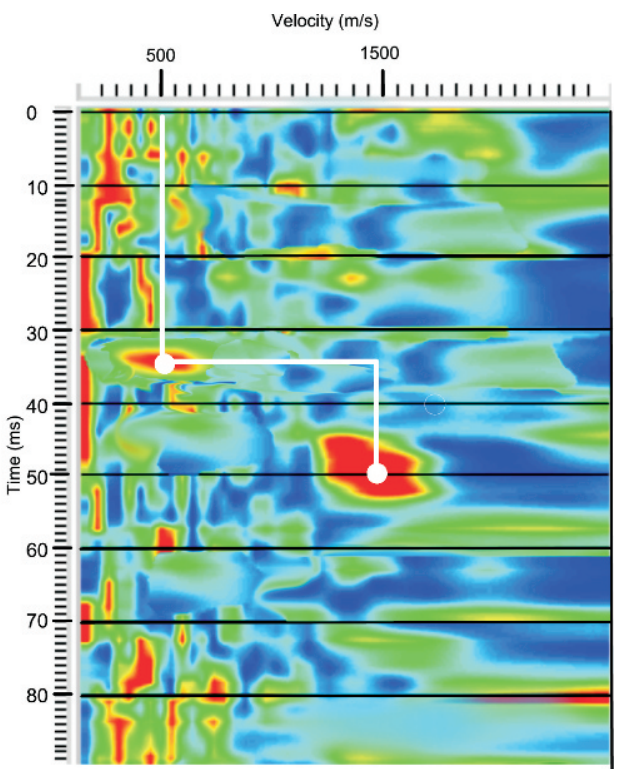

(C)

Figure 7. (A) Downhole velocity interval; (B) downhole velocity interval converted to TWT; (C) Semblance function for the CDP_ 8.875. Note the good quality of the velocity spectrum with respect to the downhole (TWT) velocity profile. CDP_8.875 location is also shown in Figure 2.

recorded data, and at depths, for doing wave-field extrapolation or downward continuation. The code used to obtain the forward modeling was slightly modified from the one proposed by Kelly and Marfurt (1990). In the analysis, we used the same geometry and sorted parameters. Table 3 reports the parameters used to carry out the synthetic seismic section of Figure 9.

Because of the small source interval $(0.25 \mathrm{~m})$, the diffraction move-out is very small and the ground roll is almost absent. In fact, the ground roll is present at low frequency (i.e., at low wave number). Figure 9 illustrates the unmigrated stacked section obtained by using the synthetic dataset. We can see a clear similarity with the stacked section of Figure 8, with a diffraction located in correspondence of the CDP_X $8.875 \mathrm{~m}$ and at $40 \mathrm{~ms}$ TWT.

\section{Discussion And Conclusions}

The aim of this research was to locate shallow cavities located in a lithoid tuff layer characterized by a strong contrast in terms of acoustic impedance. The application of the processing sequence was essential to locate the diffraction hyperbola caused by the cavity, because it doesn't appear clearly in the raw data (Fig. 8). A diffraction located over this horizon at about $40 \mathrm{~ms}$ TWT, and identifiable thanks to the presence of hyperbolic feature on the stacked section, is related to the presence of the cavity located at $10 \mathrm{~m}$ depth below ground level. To validate our results, the experimental data were compared with a theoretical section obtained by synthetic data (see Table 3). To obtain the synthetic seismic section, we used the model and the field velocity obtained by a down hole survey in Figure 7, and reported in Table 2. The features related to the diffraction hyperbolas in the theoretical and experimental data have a similar character on the unmigrated stacked sections. There is only a small horizontal shift when comparing the theoretical and experimental data, probably due to slight horizontal velocity variation. The void related to the cavity was well represented on the seismic section; and therefore, the high resolution seismic-reflection method can be useful for detection of cavities located in lithoid tuff material.

To make this detection possible, however, specific techniques must be employed. These are: 1) a short geophone spacing, which helps to improve data filtering and results in a better reduction of the ground roll signal and also helps to decrease CDP distance; 2) a short distance between shots, which increases the fold; 3) highfrequency detectors, which reduce ground-role power and increase signal resolution; 4) a 24-bit resolution seismograph; 5) adequate data processing, which should include the choice of optimal frequency and FK filters, in our case the adoption of an equivalent slope $0.005 \mathrm{~s} \mathrm{~m}^{-1}$ cut in the FK transform that resulted in successful ground-roll noise removal; and 6) whenever possible, the application of forward modeling to compare experimental with theoretical data and strengthen the obtained results.

Although the data clearly show the cavity, the void signal appears essentially as a perturbation on a stronger reflection, and thus, it is relatively subtle if compared to the background geology. Thus, seismic reflection is shown to be a suitable method for the detection of cavities in 


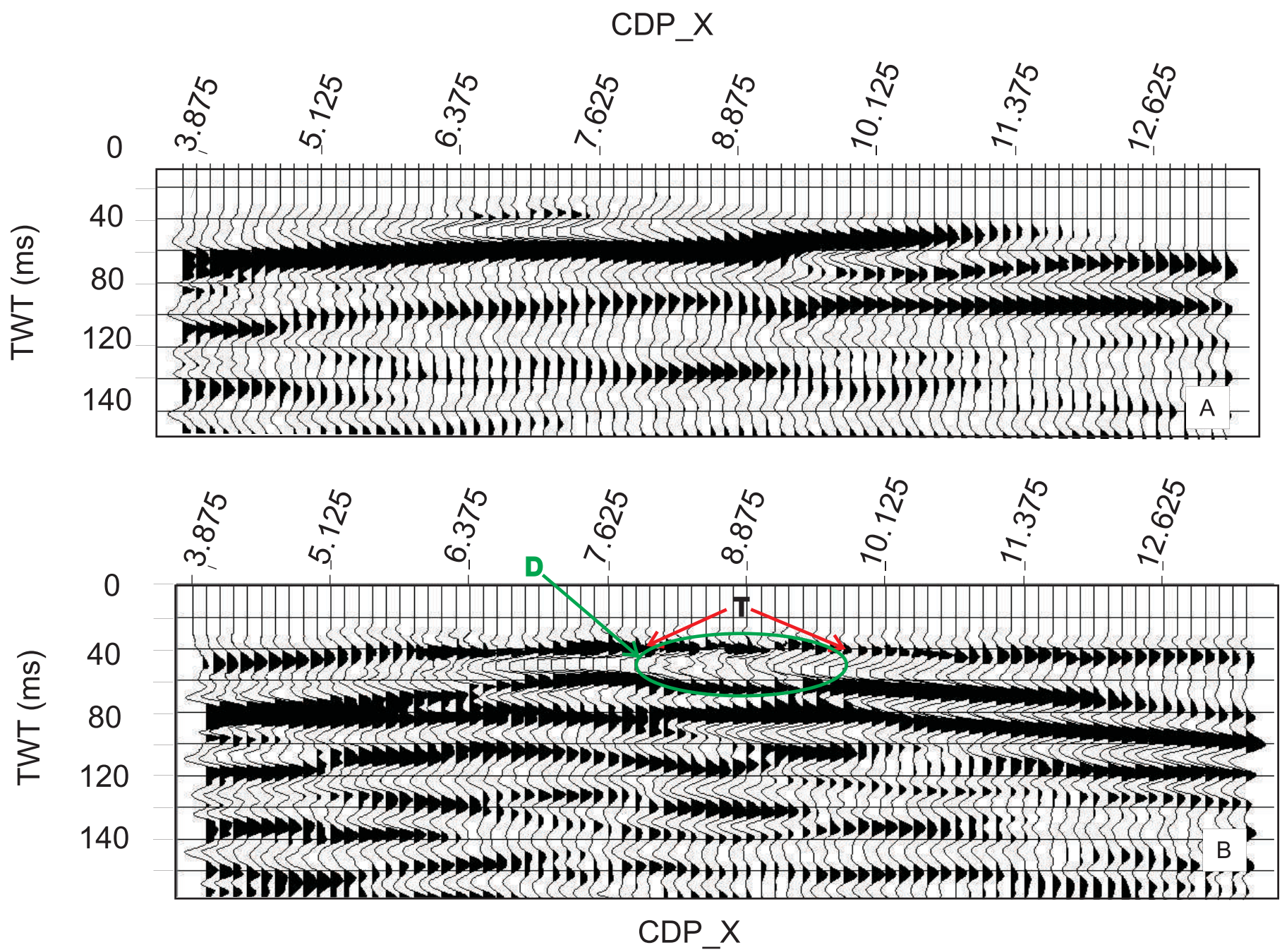

Figure 8. Unmigrated stacked section of field data before (A) and after (B) the application of the adopted processing sequences. The T horizon is related to the top of the lithoid tuff layer. Diffraction patterns $D$ appear at about $40 \mathrm{~ms}$ TWT. Such hyperbole is due to the cavity presence. We can see that high amplitude diffraction occur between the CDP_X 6.375 and 10.125 m.

CDP_X

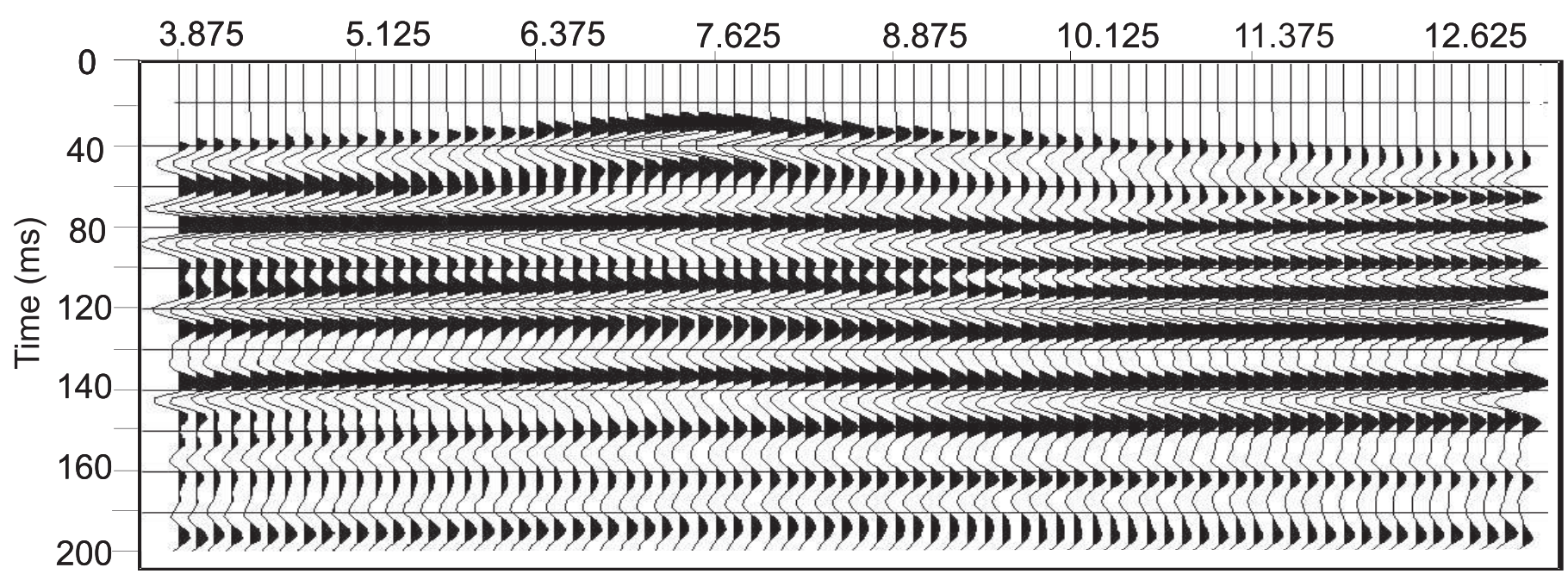

Figure 9. Unmigrated stacked section of synthetic data. It is very similar to the stacked section of field data (Fig. 8).

58• Journal of Cave and Karst Studies, April 2013 
Table 2. Wave velocities determined from downhole data and also used in the calculation of the synthetic data in Figure 9.

\begin{tabular}{lc}
\hline Depth, $\mathrm{m}$ & P-wave velocity, $\mathrm{m} \mathrm{s}^{-1}$ \\
\hline $0.00-1.50$ & 400 \\
$1.50-9.00$ & 450 \\
$9.00-19.00$ & 1500 \\
$19.00-\cdots$ & 700 \\
\hline
\end{tabular}

locations where voids occur in relatively homogeneous background materials, but voids may be difficult to resolve if host rock has other heterogeneities.

\section{ACKNOWLEDGEMENTS}

We express a special thanks to Richard Bowen for his support during the writing of this paper. Additional thanks are expressed to Dr. Anna Cicchella, Ph.D. student, University of Naples "Federico II," Dr. Antonio M. Laudiero, geologist of Afragola City, for their help in conducting the field survey and two anonymous reviewers for their valuable suggestions and corrections. Finally, we especially thank Robert Brinkmann (Associate Editor) and Malcom Field (Chief Editor) for the careful editorial handling, detailed comments, and additional review that helped to greatly improve this manuscript.

\section{REFERENCES}

Branham, K.L., and Steeples, D.W., 1988, Cavity detection using highresolution seismic-reflection methods: Mining Engineering, v. 40, p. $115-119$.

Bruno, P.P., and Rapolla, A., 1997, Location of cavities buried in the Neapolitan Yellow Tuff using the seismic reflection method: Bollettino di Geofisica Teorica e Applicata, v. 38, no. 1-2, p. 25-40.

Center for Wave Phenomena, 2007, Seismic Unix (SU) Release 40, Golden, Colorado School of Mines.

De Vivo, B., Rolandi, G., Gans, P.B., Calvert, A., Bohrson, W.A., Spera, F.J., and Belkin, H.E., 2001, New constraints on the pyroclastic eruptive history of the Campanian volcanic Plain (Italy): Mineralogy and Petrology, v. 73, p. 47-65. doi:10.1007/s007100170010.

Deino, A.L., Orsi, G., de Vita, S., and Piochi, M., 2004, The age of the Neapolitan Yellow Tuff caldera-forming eruption (Campi Flegrei caldera - Italy) assessed by ${ }^{40} \mathrm{Ar} /{ }^{39} \mathrm{Ar}$ dating method: Journal of Volcanology and Geothermal Research, v. 133, p. 157-170. doi:10.1016/ S0377-0273(03)00396-2.

Dobrin, M.B., 1976, Introduction to Geophysical Prospecting, third edition, McGraw-Hill, 630 p.

Frumkin, A., Ezersky, M., Al-Zoubi, A., Akkawi, E., and Abueladas, A.-R., 2011, The Dead Sea sinkhole hazard: Geophysical assessment of salt dissolution and collapse: Geomorphology, v. 134, no. 1-2, p. 102-117. doi:10.1016/j.geomorph.2011.04.023.

Ghiara, M.R., Lirer, L., and Munno, R., 1979, Mineralogy and geochemistry of the "low-potassium series" of the Campania volcanics (south Italy): Chemical Geology, v. 26, no. 1-2, p. 29-49. doi:10.1016/0009-2541(79)90028-7.

Grandjean, G., and Leparoux, D., 2004, The potential of seismic methods for detecting cavities and buried objects: experimentation at a test site: Journal of Applied Geophysics, v. 56, no. 2, p. 93-106. doi:10.1016/ j.jappgeo.2004.04.004.

Hunter, J.A., Pullan, S.E., Burns, R.A., Gagne, R.M., and Good, R.L., 1984, Shallow seismic reflection mapping of the overburden-bedrock
Table 3. Parameters used to carry out the synthetic seismic section.

\begin{tabular}{ll}
\hline Boundary Condition at Interfaces & \multicolumn{1}{c}{ Reflecting } \\
\hline Depth of field for modelling & $20 \mathrm{~m}$ \\
Type source & Point source model \\
Windows time length & $500 \mathrm{~ms}$ \\
Type of source wavelet & Minimum phase Ricker \\
Fundamental frequency Peak & $50 \mathrm{~Hz}$ \\
Richer & \\
$\begin{array}{ll}\text { Grid factor for step in finite } \\
\text { difference }\end{array}$ \\
\hline
\end{tabular}

interface with the engineering seismograph - some simple techniques: Geophysics, v. 49, p. 138 1-1385. doi:10.1190/1.1441766.

Inazaki, T., Yamanaka, Y., Kawamura, S., and Tazawa, O., 2004, Highresolution seismic reflection survey using Land Streamers for nearsurface cavity detection, Proceedings of 7 th SEGJ International Symposium, Sendai, Japan, p. 475-480.

Kelly, K.R., and Marfurt, K.J., eds., 1990, Numerical Modeling of Seismic Wave Propagation, Tulsa, Oklahoma, Society of Exploration Geophysicists, $525 \mathrm{p}$.

Kelly, K.R., Ward, R.W., Treitel, S., and Alford, R.M., 1976, Synthetic seismograms: a finite-difference approach: Geophysics, v. 41, p. 2-27. doi:10.1190/1.1440605.

Miller, R.D., and Steeples, D.W., 1991, Detecting voids in a 0.6-m coal seam, $7 \mathrm{~m}$ deep, using seismic reflection: Geoexploration, v. 28, p. 109-119. doi:10.1016/0016-7142(91)90043-C.

Ortolani, F., and Aprile, F., 1985, Principali caratteristiche stratigrafiche e strutturali dei depositi superficiali della Piana Campana: Bollettino della Società Geologica Italiana, v. 104, no. 2, p. 195-206.

Pánek, T., Margielewski, W., Táboř́ík, P., Urban, J., Hradecký, J., and Szura, C., 2010, Gravitationally induced caves and other discontinuities detected by $2 \mathrm{D}$ electrical resistivity tomography: Case studies from the Polish Flysch Carpathians: Geomorphology, v. 123, no. 1-2, p. 165-180. doi:10.1016/j.geomorph.2010.07.008.

Pueyo-Anchuela, Ó., Casas-Sainz, A.M., Soriano, M.A., and PocovíJuan, A., 2010, A geophysical survey routine for the detection of doline areas in the surroundings of Zaragoza (NE Spain): Engineering Geology, v. 114, p. 382-396. doi:10.1016/j.enggeo.2010.05.015.

Romano, P., Santo, A., and Voltaggio, M., 1994, L'evoluzione geomorfologica della pianura del Fiume Volturno (Campania) durante il tardo Quaternario (Pleistocene medio-superiore-Olocene): Il Quaternario, v. 7, no. 1, p. 41-56.

Sheriff, R.E., and Geldart, L.P., 1995, Exploration Seismology, second edition, Cambridge, Cambridge University Press, $628 \mathrm{p}$.

Steeples, D.W., and Miller, R.D., 1987, Direct detection of shallow subsurface voids using high-resolution seismic-reflection techniques, in Beck, B.F., and Wilson, W.L., eds., Karst Hydrogeology: Engineering and Environmental Applications, Boston, Balkema, p. 179-183.

Steeples, D.W., and Miller, R.D., 1990, Seismic-reflection methods applied to engineering, environmental, and ground-water problems, in Ward, S., ed., Geotechnical and Environmental Geophysics, V. 1, Review and Tutorial, Society of Exploration Geophysicists, Investigations in Geophysics No. 5, p. 1-30.

Taurisano, A., Tronstad, S., Brandt, O., and Kohler, J., 2006, On the use of ground penetrating radar for detecting and reducing crevassehazard in Dronning Maud Land, Antarctica: Cold Regions Science and Technology, v. 45, p. 166-177. doi:10.1016/j.coldregions.2006. 03.005 .

van Schoor, M., 2002, Detection of sinkholes using 2D electrical resistivity imaging: Journal of Applied Geophysics, v. 50, p. 393-399. doi:10.1016/ S0926-9851(02)00166-0.

Vezzoli, L., ed., 1988, Island of Ischia, Quaderni di Ricerca CNR 114, $133 \mathrm{p}$.

Yilmaz, Ö., ed., 1994, Seismic Data Processing, Tulsa, Oklahoma, Society of Exploration Geophysicists, Investigations in Geophysics no. 2, $529 \mathrm{p}$. 